\title{
Nectandra Rol. ex Rottb. (Lauraceae) no Mato Grosso do Sul, Brasil ${ }^{1}$
}

\author{
Flávio Macedo Alves² e Ângela Lúcia Bagnatori Sartori ${ }^{3,4}$
}

Recebido em 8/08/2007. Aceito em 26/05/2008

\begin{abstract}
RESUMO - (Nectandra Rol. ex Rottb. (Lauraceae) no Mato Grosso do Sul, Brasil). O trabalho apresenta o estudo taxonômico das espécies do gênero Nectandra no Mato Grosso do Sul, Brasil. Baseados na análise morfológica dos espécimes coletados em diferentes regiões do Estado são confirmados oito espécies de Nectandra: $N$. amazonum Nees, $N$. cissiflora Nees, $N$. cuspidata Nees, $N$. falcifolia (Nees) J.A. Castigl. ex Mart. Crov. \& Piccinini, N. gardneri Meisn., N. hihua (Ruiz \& Pav.) Rohwer, N. megapotamica (Spreng.) Mez e N. psammophila Nees. É fornecida uma chave de identificação para as espécies e apresentados descrições morfológicas, dados de distribuição geográfica, habitat, aspectos fenológicos, comentários taxonômicos e ilustrações para cada espécie.
\end{abstract}

Palavras-chave: centro-oeste, Lauraceae, Pantanal, taxonomia

ABSTRACT - (Nectandra Rol. ex Rottb. (Lauraceae) in Mato Grosso do Sul State, Brazil). This paper presents the taxonomic study of the species of Nectandra from Mato Grosso do Sul. Eight species of Nectandra were identified through the morphological analyses of specimens collected in different regions from the State: $N$. amazonum Nees, $N$. cissiflora Nees, $N$. cuspidata Nees, $N$. falcifolia (Nees) J.A. Castigl. ex Mart. Crov. \& Piccinini, N. gardneri Meisn., N. hihua (Ruiz \& Pav.) Rohwer, N. megapotamica (Spreng.) Mez and $N$. psammophila Nees. Identification key, morphological descriptions, geographic distribution, habitat, fenologic aspect, taxonomic comments, and illustrations are presented.

Key words: centro-oeste, Lauraceae, Pantanal, taxonomy

\section{Introdução}

Com cerca de 52 gêneros e 2.750 espécies, Lauraceae é constituída por árvores e arbustos, com a exceção de Cassytha L., uma herbácea parasita. A família é pantropical, com centros de alta diversidade de espécies no norte da América do Sul, sudeste da Ásia e Madagascar (Madriñán 2004). No Brasil ocorrem 22 gêneros e cerca de 390 espécies, com alta diversidade nas florestas pluviais e também nas restingas e no Cerrado (Barroso et al. 2002).

Com 114 espécies reconhecidas até o presente, Nectandra Rol. ex Rottb. é o segundo maior gênero de Lauraceae no Novo Mundo, depois de Ocotea Aubl. com cerca de 350 espécies (Rohwer 1993b). O gênero é restrito às Américas tropical e subtropical e quase todas as espécies ocorrem entre os trópicos de Câncer e Capricórnio, onde são encontradas desde o norte da Flórida à Argentina (van der Werff 1991). No Brasil, Nectandra encontra-se representada por 43 espécies e possui grande diversidade na floresta Amazônica e Atlântica (Baitello et al. 2003).
Nectandra está entre os mais importantes gêneros de plantas lenhosas nas regiões tropical e subtropical do continente americano, devido a sua representatividade e ampla distribuição (Rohwer \& Kubitzki 1993). O primeiro centro de diversidade do gênero se encontra nas falhas orientais dos Andes e na região da Amazônia peruana e, o segundo, no sudeste brasileiro (Rohwer 1993b).

O gênero foi descrito por Rottboell em 1778, baseado em anotações dos manuscritos de Rolander e seu posicionamento tem sido diferente entre os sistemas de classificação (Rohwer 1993b). Kostermans (1957) considera que a posição dos locelos não tem valor taxonômico para diferenciar Nectandra e Ocotea e, portanto, agrupa Nectandra e Pleurothyrium Nees como subgêneros de Ocotea. Posteriormente Allen (1966) reconhece o status de gênero de Nectandra, Ocotea e Pleurothyrium, através da posição dos locelos.

Segundo Rohwer (1991), algumas espécies podem se aproximar do conceito central do seu gênero, enquanto outras se tornam próximas para um gênero, porém com afinidades óbvias entre outros gêneros. Por essa razão, o caráter posição dos locelos quando adotado

\footnotetext{
1 Parte da Dissertação de Mestrado do primeiro Autor, desenvolvido na Universidade Federal de Mato Grosso do Sul

2 Universidade de São Paulo, ESALQ, Herbário ESA, Av. Pádua Dias 11, C. Postal 9, 13418-900 Piracicaba, SP, Brasil (flaurace@ yahoo.com.br)

3 Universidade Federal de Mato Grosso do Sul, Cidade Universitária s.n., Laboratório de Botânica, Herbário CGMS, 79070-900 Campo Grande, MS, Brasil

4 Autor para correspondência: angela.sartori@uol.com.br
} 
como caráter único tem conduzido a equívocos na separação de Nectandra, Pleurothyrium e Ocotea, porém, é extremamente útil se usado em combinação com outros caracteres (Rohwer \& Kubitzki 1985). Bernardi (1962), van der Werff (1991) e Rohwer (1993a; b), tratam Nectandra, Ocotea e Pleurothyrium separadamente.

Filogeneticamente, Nectandra encontra-se posicionado no clado terminal da família Lauraceae e, a partir da atual circunscrição (Rohwer 1993b), o gênero não é monofilético e está relacionado com Pleurothyrium (Rohwer 2000). Chanderbali et al. (2001) colocam Nectandra no clado de Lauraceae com maior diversidade nos neotrópicos, designado como complexo Ocotea. Segundo o autor, o gênero Nectandra é polifilético e possui dois ramos, as espécies do grupo Nectandra coriacea sensu Rohwer (1993b) como elementos basais em relação ao posicionamento das espécies de Nectandra s.st., que emergiu como grupo irmão de Pleurothyrium.

Na última revisão taxonômica de Nectandra, Rohwer (1993b) divide o gênero em 11 grupos informais. Segundo o autor, Nectandra possui diferenciação infragenérica importante com alguns grupos informais muito homogêneos, mas outros, fracamente delimitados, com algumas espécies sem posição certa. Por essa razão, o autor não formaliza o estabelecimento de categorias infragenéricas para Nectandra.

Entre os trabalhos clássicos realizados com Lauraceae incluindo Nectandra, destacam-se os de Nees (1836) e Mez (1889). Importantes contribuições sobre as espécies neotropicais são de Kostermans (1957), Allen (1966), van der Werff (1984), Rohwer \& Kubitzki (1985), van der Werff (1991), Rohwer et al. (1991) Rohwer (1991; 1993a; b), Rohwer \& Kubitzki (1993), van der Werff \& Richter (1996). No Brasil, destacamse Barroso (1949), Vattimo-Gil (1956; 1966), Coe-Teixera (1975), Pedralli (1986; 1987), Baitello \& Coe-Teixeira (1987), mais recentemente, os de Vicentini et al. (1999), Quinet \& Andreata (2002), Baitello et al. (2003), Moraes (2005), Quinet (2005), Assis et al. (2005), Kropf et al. (2006) e Alves \& Ishii (2007).

Os inventários botânicos têm revelado que Lauraceae está em termos florísticos e econômicos, entre as mais importantes famílias de angiospermas, mas, infelizmente, a identificação de suas espécies é tarefa difícil (Baitello 2001). Por ser uma família de difícil identificação e aliado a pouca citação acerca da família na literatura local, fez-se necessário este estudo, a fim de subsidiar estudos florísticos, fitossociológicos, ecológicos, de conservação e recuperação de áreas degradadas no Pantanal.

O presente trabalho teve como objetivo realizar o tratamento taxonômico de Nectandra do Mato Grosso do Sul, fornecer uma chave de identificação, ilustrações das espécies, bem como disponibilizar dados atualizados da floração, frutificação, distribuição geográfica e ambiente preferencial de cada táxon.

\section{Material e métodos}

Para a realização do presente estudo foi examinado exsicatas pertencentes a herbários nacionais os quais mantém coleções sul-mato-grossenses de Nectandra. Foram verificadas coleções dos herbários BHCB, CGMS, COR, CPAP, ESA, FUEL, HB, HRCB, HUFU, IAC, INPA, JBRJ, MBM, RB, SP, SPF, SPSF, UB, UEC, UFMT e UPCB (siglas segundo Holmgreen et al. 1990) e os não indexados no Index Herbariorum CEUL, HISA e HSJRP. Coletas foram realizadas em diferentes regiões do Mato Grosso do Sul, sendo os espécimes herborizados e incorporados aos herbários CGMS e COR. Foi confeccionada uma chave de identificação baseada em caracteres morfológicos, com ênfase nos florais e foliares. A nomenclatura morfológica adotada nas descrições foi baseada em Font Quer (1953), Radford et al. (1974) e Harris \& Harris (1994) e o padrão de nervação, segundo Hickey (1973).

A distribuição geográfica e o ambiente preferencial das espécies foram obtidos a partir das observações de campo e informações contidas nas etiquetas que acompanham o material herborizado. As formações vegetacionais foram classificadas de acordo com Veloso (1992).

As ilustrações foram confeccionadas com o auxílio de uma câmara clara acoplada a um estereomicroscópio Zeiss, utilizando material coletado em campo e quando necessário, herborizado e hidratado.

\section{Resultados e discussão}

Nectandra Rol. ex Rottb. Acta Lit. Univ. Hafn. 1: 279. 1778.

Árvores. Folhas simples, alternas, raro opostas e subopostas, eucamptódroma e broquidódroma, domácias presentes, geralmente em tufos de tricomas, raramente escavadas ou ausentes. Inflorescências tirsóide-paniculadas e racemiformes. Flores monóclinas, hipanto raso a profundo, internamente glabro a piloso, tépalas 6, iguais a subiguais (horizontalmente organizadas na antese), pouco a densamente papilosas; estames férteis 9 , tetralocelados, dispostos em 4 séries, anteras das séries I e II, com locelos introrsos, dispostos em linha horizontal ou formando um arco, anteras da série III com locelos extrorsos ou os superiores latrorsos, filete dos estames da série III com 2 glândulas na base, série IV estaminodial, estaminódios desenvolvidos ou não, capitados ou clavados; ovário livre. Fruto baga 
monospérmica, cúpula pateriforme a hemisférica.

Dados bibliográficos indicam a presença de 10 espécies de Nectandra para o Mato Grosso do Sul (Dubs 1998; Damasceno Júnior et al. 2000; Alves \& Ishii 2007; Battilani et al. 2004; Pott et al. 2006). Porém, no presente trabalho são confirmadas oito espécies do gênero, a saber, $N$. amazonum Nees, $N$. cissiflora Nees, $N$. cuspidata Nees, $N$. falcifolia (Nees) J.A. Castigl. ex Mart. Crov. \& Piccinini, N. gardneri Meisn., N. hihua (Ruiz \& Pav.) Rohwer, N. megapotamica (Spreng.) Mez e N. psammophila Nees. N. membranacea (Sw.) Griseb. (Battilani et al. 2004), N. grandiflora Nees (Pott et al. 2006) são citadas para o Mato Grosso do Sul, mas não foram confirmadas no presente trabalho.
No Estado, espécies do gênero podem ser encontradas em floresta estacional semidecidual, floresta ombrófila densa aluvial e somente $N$. cuspidata ocorre na savana florestada.

Dos 11 grupos informais que Rohwer (1993b) propõe para Nectandra, seis têm representantes no Mato Grosso do Sul. N. amazonum faz parte do grupo Nectandra amazonum enquanto $N$. falcifolia, $N$. megapotamica e $N$. psammophila integram o grupo Nectandra megapotamica. $N$. cissiflora está incluída no grupo Nectandra cissiflora, $N$. cuspidata no grupo Nectandra membranacea, $N$. gardneri no grupo Nectandra grandiflora e N. hihua no grupo Nectandra hihua.

\section{Chave para identificação das espécies de Nectandra em Mato Grosso do Sul, Brasil}

1. Conectivo das anteras das séries I e II com prolongamento igual ou superior 50\% do comprimento da antera

2. Folhas com ambas as faces pubescentes 1. N. amazonum

2. Folhas com face adaxial glabrescentes a glabras e face abaxial glabrescente

3. Anteras dos estames da série II com ápice não contraído acima dos locelos formando um acume; estilete levemente menor que o ovário, cerca de $45 \%$ do pistilo

3. Anteras dos estames da série II com ápice fortemente contraído acima dos locelos formando um acume; estilete muito menor que o ovário, cerca de $15 \%$ do pistilo 6. N. hihua

1. Conectivo das anteras das séries I e II com prolongamento inferior a $45 \%$ do comprimento da antera

4. Folhas largamente obovadas ou largamente ovadas . 2. N. cissiflora

4. Folhas elípticas, estreito-elípticas a lanceoladas

5. Filetes dos estames das séries I e II cerca de 1/5 do comprimento das anteras ou mais curtos

6. Folhas 7-12 vezes mais longas que largas; estilete do mesmo tamanho que o ovário, cerca de $50 \%$ do pistilo 4. N. falcifolia

6. Folhas 3-5 vezes mais longas que largas; estilete menor que o ovário, cerca de $20 \%$ do pistilo 8. N. psammophila

5. Filetes dos estames das séries I e II cerca de 1/3 ou 1/2 do comprimento da antera

7. Folhas de face abaxial densamente serícea; anteras da série I e II transverso-elípticas, ápice não apiculado 3. N. cuspidata

7. Folhas de face abaxial com tricomas esparsos; anteras da série I e II quadrangulares a retangulares, ápice apiculado 7. N. megapotamica

1. Nectandra amazonum Nees, Syst. Laur. 282. 1836. Fig. 1-4

Árvore, até $16 \mathrm{~m}$ alt. Folhas alternas, lâminas (11-)14-17(-23,5)×(2,3-)3,5-4,5(-5,3) cm, 3-5,5 vezes mais longas que largas, elípticas, lanceoladas, raramente ovado-elípticas, ápice acuminado, base aguda, raramente obtusa ou assimétrica, margem inteira, face adaxial glabrescente a pubescente, face abaxial pubescente, nervuras laterais 6-11 pares, nervação eucamptódroma, ápice geralmente broquidódroma, domácias entre a nervura primária e a secundária, em forma de tufos de tricomas em algumas folhas; pecíolo 10-20×1,1-1,8 mm, pubescente, levemente achatado. Inflorescência $3-10 \mathrm{~cm}$ compr., tirsóide-paniculada, axilar ou terminal, comprimento menor que as folhas, tricomas densos, curtos e adpressos, pedúnculo 2,5-5 $\mathrm{cm}$ compr. Flores 7-11 mm diâm., tricomas densos, curtos e adpressos, hipanto internamente glabro; tépalas subiguais, tépalas externas $3,8 \times 3,7 \mathrm{~mm}$, ovadas a largo-ovadas, ápice acuminado a arredondado, densamente papilosas, tépalas internas $3 \times 2 \mathrm{~mm}$, ovadas, elípticas a estreito-elípticas, ápice arredondado a acuminado, densamente papilosas em ambas as faces, pedicelo 1-3,7 mm compr.; conectivo dos estames das séries I e II com prolongamento igual ou superior a $50 \%$ do comprimento da antera, anteras densamente papilosas, filetes dos estames das séries I e II 1/5 do comprimento da antera ou mais curtos, anteras 
ovado-triangulares, ápice acuminado a arredondado, antera dos estames da série II com conectivo levemente contraído acima dos locelos, anteras dos estames da série III obtrapeziformes, ápice arredondado a truncado, estaminódios conspícuos, subcapitados, bem fusionados com os estames da série III; pistilo ca. 2,6 mm compr., ovário globoso, glabro, estilete ca. $50 \%$ do pistilo. Fruto ca. $19 \times 10 \mathrm{~mm}$, elíptico, ca. $45 \%$ envolvido pela cúpula, cúpula ca. $9 \times 5 \mathrm{~mm}$, trompetiforme, pedicelo ca. $4 \mathrm{~mm}$ compr., engrossado.

Material examinado: BRASIL. Mato Grosso do Sul: Corumbá, 4/V/2001, fl., Damasceno-Júnior 2304 (COR, SPF); 17/X/2002, fr., Bortolloto et al. 1140 (COR).

Nectandra amazonum é uma espécie característica da Amazônia brasileira, alcançando o nordeste das Guianas até o sudeste da Bolívia (Rohwer 1993b) e Mato Grosso do Sul. É provavelmente a mais característica espécie da floresta inundada ao longo do rio Amazonas e seus tributários (Rohwer 1993b). No Mato Grosso do Sul a espécie é encontrada na floresta ombrófila densa aluvial do rio Paraguai, a noroeste do estado, na região do Pantanal, município de Corumbá, próximo ao Parque Nacional do Pantanal. Coletada com flores em maio e com frutos em outubro.

Nectandra amazonum pode ser reconhecida por suas folhas geralmente lanceoladas, freqüentemente pubescentes em ambas as faces, flores de 7 a $11 \mathrm{~mm}$, estames das séries I e II com conectivos longos. Os estames da série II apresentam o ápice da antera levemente contraído acima dos locelos e a conexão entre os locelos e o conectivo é proeminente Além disso, os estaminódios da IV série são bem fusionados com os estames da série III.

Segundo Rohwer (1993b), uma das características diagnósticas da espécie são suas folhas geralmente opostas, porém, essa característica não foi verificada nos materiais do Mato Grosso do Sul.

2. Nectandra cissiflora Nees, Syst. Laur. 296. 1836.

Fig. 5-8

Árvore, até $20 \mathrm{~m}$ alt. Folhas alternas, lâminas $(8,5-) 13-22(-28) \times(4,8-) 6-11(-14,5) \mathrm{cm}, 1,4-3$ vezes mais longas que largas, obovadas, largo obovadas, largoelípticas a largamente ovadas, ápice acuminado a obtuso, base aguda e levemente revoluta, margem inteira, face adaxial glabrescente, face abaxial com tricomas densos, curtos, crespos e adpressos, nervuras laterais 7-14 pares, nervação eucamptódroma, no ápice geralmente broquidódroma, domácias raramente presentes entre a nervura primária e a secundária, escavadas na base foliar; pecíolo 10-30×2-3,4 mm, tricomas curtos, crespos e densos, levemente achatados. Inflorescência 9-22 cm compr., tirsóide-paniculada, axilar ou terminal, comprimento geralmente maior que as folhas, glabrescente ou com tricomas densos, curtos, patentes e crespos, pedúnculo 1,5-8,5 $\mathrm{cm}$ compr. Flores 4-5 mm diâm., glabrescente ou com tricomas densos, curtos e crespos, hipanto internamente glabro; tépalas iguais, 1,7-2,2×1,1-1,4 mm, elípticas a ovadas, ápice obtuso, densamente papilosas na face interna, pedicelo 1,5-6 mm compr.; conectivo dos estames das séries I e II com prolongamento inferior a $45 \%$ do comprimento da antera, anteras densamente papilosas na face abaxial, filete dos estames das séries I e II 1/5 do comprimento da antera ou mais curtos, anteras transverso-elípticas, ápice arredondado a emarginado, antera dos estames da série II com conectivo não contraído acima dos locelos, anteras dos estames da série III obtrapeziformes, ápice truncado, estaminódios inconspícuos, subclavados a estipitiformes; pistilo ca. 1,6 mm compr., ovário elíptico, glabro, estilete menor que o ovário, ca. $35 \%$ do pistilo. Fruto ca. $16 \times 11 \mathrm{~mm}$, globoso a elíptico, ca. $15 \%$ envolvido pela cúpula, cúpula ca. $3 \times 7 \mathrm{~mm}$, pateriforme a trompetiforme, pedicelo ca. $10 \mathrm{~mm}$ compr., engrossado.

Material examinado: BRASIL. Mato Grosso do Sul: Anaurilândia, 15/X/1998, fr., Amaral 232 (CGMS, RB). Aquidauana, 16/X/1972, fl., Hatschbach 30490 (INPA). 11/IX/1987, fl., M.C. 8 (CGMS); 16/X/1995, fl., Hatschbach \& Barbosa 63420 (ESA); 11/VIII/1970, fl., Hatschbach 24568 (INPA). Bataguaçu, 20/XI/1992, fr., Cordeiro et al. 963 (SP). Bataiporã, 29/X/1986, fl., Pastore \& Klein 165 (RB). Corguinho, 20/VIII/2006, fl., Pott \& Pott 13103 (HMS). Corumbá, 9/XI/1999, fl., Resende 84 (COR, ESA). Rio Negro, 26/VIII/1998, fl. fr., Pott 3507 (CGMS, CPAP); 26/VIII/1998, fl., Pott 3555 (CGMS, CPAP). Rochedo, 28/VIII/1998, fl., Damasceno-Júnior 1547 (CGMS).

Nectandra cissiflora ocorre do sul do México ao sul do Brasil (Rohwer 1993b). No Mato Grosso do Sul, a espécie é encontrada na floresta ombrófila densa aluvial e floresta estacional semidecidual nas regiões central, leste e oeste. Coletada com flores e frutos de agosto a novembro.

Nectandra cissiflora é a maior árvore do gênero no Mato Grosso do Sul, caracterizada por inflorescência geralmente maior que as folhas, flores pequenas, cerca de $4 \mathrm{~mm}$, com papilas longas nas tépalas e anteras, filetes dos estames das séries I e II muito curtos, cerca de 1/5 do comprimento da antera ou mais curtos, anteras transverso-elípticas, receptáculo raso e estilete menor que o ovário, cerca de $35 \%$ do pistilo.

3. Nectandra cuspidata Nees, Syst. Laur. 330. 1836.

Fig. 9-12

Árvore, até $18 \mathrm{~m}$ alt. Folhas alternas, lâminas $(6,5-) 10-16(-21) \times(1,5-) 2-3(-4,5) \mathrm{cm}, 3-7$ vezes mais 
longas que largas, lanceoladas, elípticas a estreitoelípticas, geralmente falciformes, ápice cuspidado, base aguda a atenuada, revoluta na base, margem inteira, face adaxial glabrescente a glabra, face abaxial densamente serícea, nervuras laterais 4-11 pares, padrão de nervação eucamptódroma, domácias ausentes; pecíolo 4-17×0,8-2 mm, com tricomas curtos, crespos e densos, canaliculado. Inflorescência 3,5-12 cm compr., tirsóidepaniculada, axilar ou terminal, comprimento igual a menor que as folhas (geralmente menor), tricomas curtos,
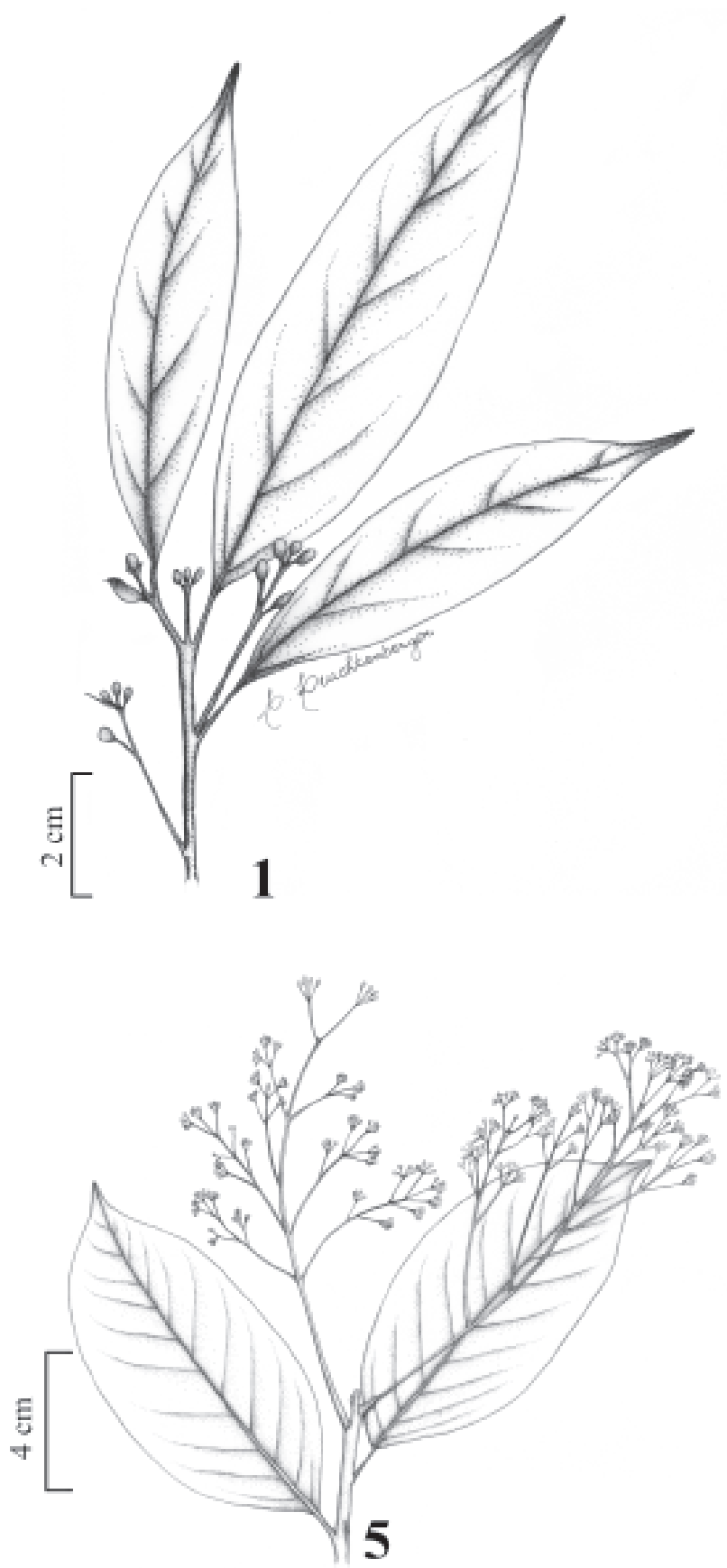

crespos e densos, aumentando a densidade em direção à flor, pedúnculo 1,5-6 cm compr. Flores 4-5 mm diâm., com tricomas curtos, crespos e densos, hipanto internamente glabro ou com tricomas esparsos, curtos e adpressos; tépalas iguais, 1,7-2×1-1,5 mm, elípticas a oblongas, ápice obtuso, esparsamente papilosas, pedicelo 1-3 mm compr.; conectivo dos estames das séries I e II com prolongamento inferior a $45 \%$ do comprimento da antera, anteras esparsamente papilosas, filete dos estames das séries I e II 1/2 a 1/3 do comprimento da antera ou

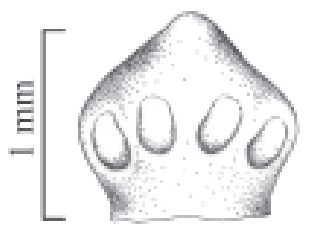

2
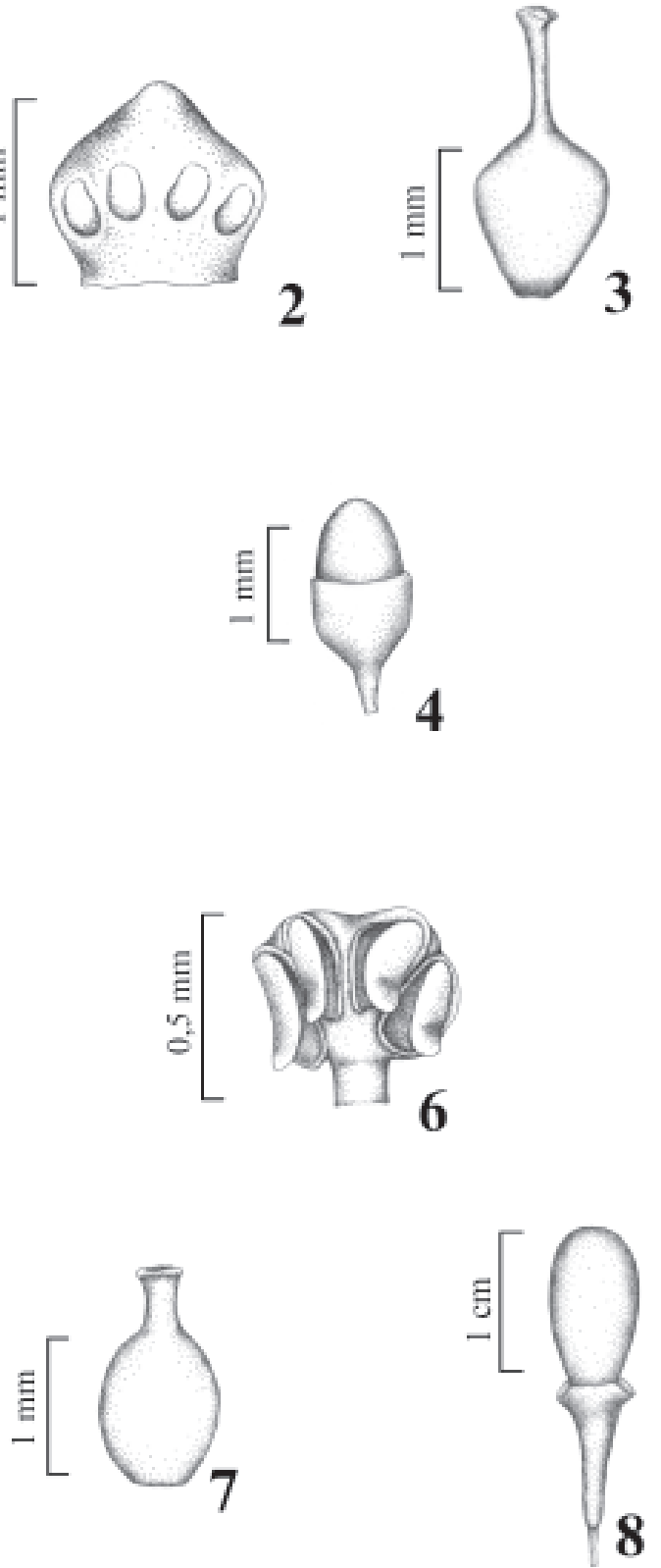

Figuras 1-8. 1-4. Nectandra amazonum Nees. 1. Ramo com frutos. 2. Estame da série I. 3. Pistilo. 4. Fruto (Bortolloto 1140). 5-8. Nectandra cissiflora Nees. 5. Ramo com flores. 6. Estame da série I. 7. Pistilo. 8. Fruto (Pott 3555). 
pouco menor, anteras tranverso-elípticas, ápice obtuso, antera dos estames da série II com conectivo não contraído acima dos locelos, anteras dos estames da série III obtrapeziformes, ápice truncado, estaminódios inconspícuos, estipitiformes, bem fusionados com os estames da série III; pistilo ca. $2 \mathrm{~mm}$ compr., ovário elíptico, glabro, estilete do mesmo tamanho a pouco maior que o ovário, ca. 50 a $60 \%$ do pistilo. Fruto ca. $10 \times 6 \mathrm{~mm}$, globoso a elíptico, ca. $20 \%$ envolvido pela cúpula, cúpula ca. $2,3 \times 4,5 \mathrm{~mm}$, infundibuliforme a pateriforme, pedicelo ca. $6,5 \mathrm{~mm}$ compr., pouco engrossado.

Material examinado: BRASIL. Mato Grosso do Sul: Anaurilândia, 22/IV/2002, fl., Pott et al. 9714 (HMS); 22/IV/2002, fl., Pott et al. 9680 (HMS).Caarapó, 24/IX/2001, fr., Sciamarelli \& Silva 1016 (CGMS); 23/I/2001, fr., Sciamarelli et al. 835 (CGMS). Camapuã, 26/VIII/1973, fr., Hatschbach 32357 (INPA). Anaurilândia, 28/XI/1992, fr., Catharino et al. 1889 (SP). Campo Grande, 5/II/2001, fl., Garcez s.n. (CGMS 11267); 23/I/2003, fl., Rodrigues 77 (CGMS); 25/II/1987, fl., Conceição 2008 (CGMS, RB); 7/IX/1986, fr., Conceição 1919 (CGMS); 5/II/2003, fl., Garcez s.n. (CGMS 11265); 9/III/1987, fl., Conceição 2024 (RB); 23/VIII/2005, Alves \& Garcez 27 (CGMS); 25/IV/2002, fl., Pott 9806 (HMS). Iguatemi, 7/II/1993, fl., Hatschbach 58604 (UB); 18/IX/2003, fr., Oliveira 5 (RB). Costa Rica, 1/IV/2004, fl., Pott et al. 11624 (HMS, CGMS); 1/IV/2004, fl., Pott et al. 11625 (HMS, CGMS). Naviraí, 23/X/1986, fr., Pastore \& Klein 111 (RB). São Gabriel do Oeste, 21/IV/1996, fr., Ratter 7491 (UB). Sidrolândia, 12/IV/1972, fl., Hatschbach 29434 (INPA).

Nectandra cuspidata é uma das mais freqüentes e bem distribuídas espécies do gênero, encontrada do sul do México ao Paraguai (Rohwer 1993b.) No Mato Grosso do Sul a espécie pode ser coletada na floresta ombrófila densa aluvial e na savana florestada das regiões central, norte, sul e leste. Coletada com flores de janeiro a abril e com frutos de setembro a janeiro.

Nectandra cuspidata pode ser reconhecida por suas folhas lanceoladas, com um longo acume, geralmente falcadas, domácias ausentes, flores pequenas, cerca de 4-5 $\mathrm{mm}$, receptáculo profundo, papilosidade esparsa nas tépalas e estames e estilete com cerca de 50 a $60 \%$ do tamanho do pistilo.

$N$. cuspidata pode ser confundida com N. membranacea (Sw.) Griseb., porém a primeira possui folhas com a face abaxial densamente serícea e filete dos estames das séries I e II com cerca de $1 / 2$ a 1/3 do comprimento da antera ou pouco menor que a antera, enquanto $N$. membranacea, apresenta folhas com face abaxial com tricomas esparsos e filete dos estames das séries I e II pouco mais curto ou mais longo que as anteras. Portanto, apesar de ser citada para o Mato Grosso do Sul (Lorenzi 2000), N. membranacea não foi confirmada para o estado.

Na maioria das coletas analisadas de $N$. cuspidata, dos anos 70, 80 e início dos anos 90, a espécie está identificada como sinonímia de $N$. pichurim Kunth. Mez (1889) sinonimizou as duas espécies, enquanto Rohwer (1993b) separa as duas espécies e considera que N. pichurim possui uma cúpula mais profunda e fruto mais alongado, sendo encontrada na Colômbia e Venezuela, enquanto $N$. cuspidata tem cúpula mais rasa e fruto geralmente elíptico e é coletada do México ao Paraguai e Brasil.

4. Nectandra falcifolia (Nees) J.A. Castigl. ex Mart. Crov. \& Piccinini, Revista Invest. Agríc. 4: 206. 1950. Fig. 13-16

Árvore, até $8 \mathrm{~m}$ alt. Folhas alternas, lâminas (8-)10-12(-15,5)×(0,7-)1-1,5(-2) cm, 7-12 vezes mais longas que largas, lanceoladas, estreito-elípticas a lineares, freqüentemente falciformes, ápice agudo a cuspidado, base atenuada a aguda, margem inteira, face adaxial glabra, face abaxial glabrescente, nervuras laterais 7-11 pares, nervação eucamptódroma, no ápice geralmente broquidódroma, domácias entre a nervura primária e a secundária, em forma de tufos de tricomas na maioria das folhas; pecíolo 4-12×0,6-1,4 mm, glabrescente, levemente achatado. Inflorescência $4-8 \mathrm{~cm}$ compr., tirsóide-paniculada, axilar ou terminal, comprimento geralmente menor que as folhas, raro igual, tricomas esparsos e adpressos, pedúnculo 2-4 cm compr. Flores 4-6 diâm., tricomas esparsos, adpressos, diminuindo em direção ao ápice, hipanto internamente glabro; tépalas iguais, 2,5-3×1,2-1,4 mm, elípticas, ovadas a oblongas, ápice agudo, esparsamente papilosas, pedicelo 1,3-3 mm compr.; conectivo dos estames das séries I e II com prolongamento inferior a $45 \%$ do comprimento da antera, anteras esparsamente papilosas, filete dos estames das séries I e II 1/5 do comprimento da antera ou mais curtos, anteras quadrangulares, ápice truncado, antera dos estames da série II com conectivo não contraído acima dos locelos, anteras dos estames da série III retangulares a obtrapeziformes, ápice truncado, estaminódios conspícuos, levemente clavados; pistilo ca. 2,1 mm compr., ovário elíptico, glabro, estilete do mesmo tamanho do ovário, ca. de $50 \%$ do pistilo. Fruto ca. $10 \times 6 \mathrm{~mm}$, elíptico, ca. $35 \%$ envolvido pela cúpula, cúpula ca. $3,7 \times 7 \mathrm{~mm}$, trompetiforme, pedicelo ca. $9 \mathrm{~mm}$ compr., pouco engrossado.

Material examinado: BRASIL. Mato Grosso do Sul: Anaurilândia, 19/VI/1998, fl., Salvador et al. 59 (RB, CGMS). Bataguassu, 24/XI/1992, fr., Cordeiro et al. 
1187 (SP). Três Lagoas, 13/X/1998, fr., Amaral et al. 95 (CGMS, RB); 13/X/1998, fl., Amaral et al. 94 (CGMS); 16/X/1998, fr., Bicudo et al. 210 (CGMS); 7/IV/1999, fl., Amaral et al. 294 (CGMS); 7/IV/1999, fl., Amaral et al. 321 (CGMS).

Nectandra falcifolia ocorre no sul da América do Sul, do Brasil até a região de La Plata na Argentina (Rohwer 1993b). No Mato Grosso do Sul a espécie ocorre na floresta ombrófila densa aluvial do rio Paraná e afluentes, na região leste e sudeste do estado. Coletada com flores de junho a outubro e com frutos de outubro a novembro.

Nectandra falcifolia apresenta folhas lanceoladas, estreito-elípticas a lineares, geralmente falciformes, até 12 vezes mais longas que largas. A espécie é comumente confundida com N. megapotamica e, segundo Rohwer \& Kubitzki (1993) e Baitello et al. (2003), N. falcifolia é afim e reconhecida como parcialmente simpátrica de N. megapotamica.

Nectandra falcifolia possuem folhas 7-12 vezes mais longas que largas, domácias entre a nervura primária e a secundária, em tufos de tricomas, encontrado na maioria das folhas e filete dos estames das séries I e II $1 / 5$ do comprimento da antera. Por outro lado, $N$. megapotamica possui folhas 4-6,5 vezes mais longas que largas, domácias ocasionais entre a nervura primária e a secundária, em forma de tufos de tricomas, sendo encontrada em poucas folhas de um mesmo indivíduo e filete dos estames das séries I e II com $1 / 3$ ou $1 / 2$ do comprimento da antera.

Rohwer (1993b) sinonimizou N. falcifolia em $N$. angustifolia, porém, o autor relata não estar totalmente certo do nome correto desse táxon, pois o material da coleção tipo e sua origem geográfica são duvidosos. Até novas informações adota-se aqui $N$. falcifolia.

5. Nectandra gardneri Meisn., A.P. de Candolle, Prodr. 15(1): 155. 1864.

Fig. 17-20

Árvore a arbusto, até $10 \mathrm{~m}$ alt. Folhas alternas a opostas, lâminas $(6,5-) 10-15(-19,5) \times(3-) 4-5(-8,5) \mathrm{cm}$, $1,5-3$ vezes mais longas que largas, ovadas, largo-ovadas, largo-lípticas, ovado-elípticas e raro lanceoladas, ápice acuminado, raro retuso e obtuso, base levemente atenuada, raro aguda, margem inteira, levemente revoluta, face adaxial glabrescente a glabra, face abaxial glabrescente, nervuras laterais 5-8 pares, nervação eucamptódroma, no ápice geralmente broquidódroma, domácias entre a nervura primária e a secundária, em forma de tufos de tricomas; pecíolo 5-19×1,1-2,6 mm, glabrescente, canaliculado. Inflorescência $9-20 \mathrm{~cm}$ compr., tirsóide-paniculada, axilar ou terminal, comprimento igual ou menor que as folhas, glabra, tricomas crespos, adpressos e densos, raramente glabrescente, pedúnculo 3,5-9,2 cm compr. Flores 7-9 mm diâm., tricomas densos, crespos e adpressos, hipanto internamente glabro ou com tricomas esparsos; tépalas subiguais, tépalas externas ovadas, 2,6-3,3x 1,8-2,5 mm, tépalas internas elípticas, 2,6-3,3× 1,8-2,5 mm, ápice arredondado a agudo, densamente papilosas, pedicelo 1,1-4,8 mm compr.; conectivo dos estames das séries I e II com prolongamento igual ou superior a $50 \%$ do comprimento da antera, anteras esparsamente papilosas, filetes dos estames das séries I e II 1/5 do comprimento da antera ou mais curtos, anteras pentagonais, ápice agudo, arredondado a truncado, antera dos estames da série II com conectivo não contraído acima dos locelos, anteras dos estames da série III obtrapeziformes, ápice obtuso a truncado, estaminódios conspícuos, triangulares ou glandulares; pistilo ca. 2,2 mm compr., ovário elíptico, glabro, estilete levemente menor que o ovário, ca. $45 \%$ do pistilo. Fruto ca. $12,5 \times 8 \mathrm{~mm}$, elíptico, ca. $35 \%$ envolvido pela cúpula, cúpula ca. $5,5 \times 8,5 \mathrm{~mm}$, trompetiforme, pedicelo ca. $6,5 \mathrm{~mm}$ compr., pouco engrossado.

Material examinado: BRASIL. Mato Grosso do Sul: Água Clara, 22/IV/2005, fl., Pott \& Pott 7770 (HMS). Campo Grande, 15/IX/1988, fr., Silva 126 (CGMS, ESA); 21/III/1992, fl., Cação \& Farias 22 (CGMS); 12/VI/1988, fl., Fugileayashi s.n. (CGMS 42); 14/IX/2005, Alves 28 (CGMS); 15/VII/2005, Alves 29 (CGMS); 8/VI/1988, fl., Carmo s.n. (CGMS 84); 3/V/1983, fl., Júnior s.n. (CGMS 41); 30/IV/1990, fl., Resende 93 (CGMS); 19/VI/1990, fl., A.O. s.n. (CGMS 3079); 3/V/1983, fl., S.F.J. s.n. (CGMS 1882); 14/IV/2002, fl., Pott 5303 (HMS) Corumbá, 13/VI/2002, Smael et al. 09 (COR). Inocência, 21/IV/2004, fl., Penha et al. 1957 (CGMS). Rio Brilhante, 19/IV/1972, fl., Hatschbach 29617 (INPA).

Nectandra gardneri é endêmica do Brasil, ocorre no Cerrado da região centro-oeste e sudeste brasileiro (Rohwer 1993b). No Mato Grosso do Sul a espécie é encontrada na floresta ombrófila densa aluvial nas regiões central, nordeste e oeste. Coletada com flor de março a junho e com fruto de agosto a setembro.

Nectandra gardneri é reconhecida por folhas geralmente ovadas e frequentemente opostas, nervuras amareladas na face adaxial nos espécimes desidratados, estilete pouco menor que o ovário, cerca de $45 \%$ do pistilo e cúpula trompetiforme, envolvendo cerca de $35 \%$ do fruto.

No Mato Grosso do Sul, a espécie é freqüentemente confundida com $N$. hihua, porém $N$. gardneri possui estames da série II com conectivo não contraído e estilete levemente menor que o ovário, cerca de $45 \%$ da altura do pistilo, enquanto $N$. hihua, tem anteras dos estames 


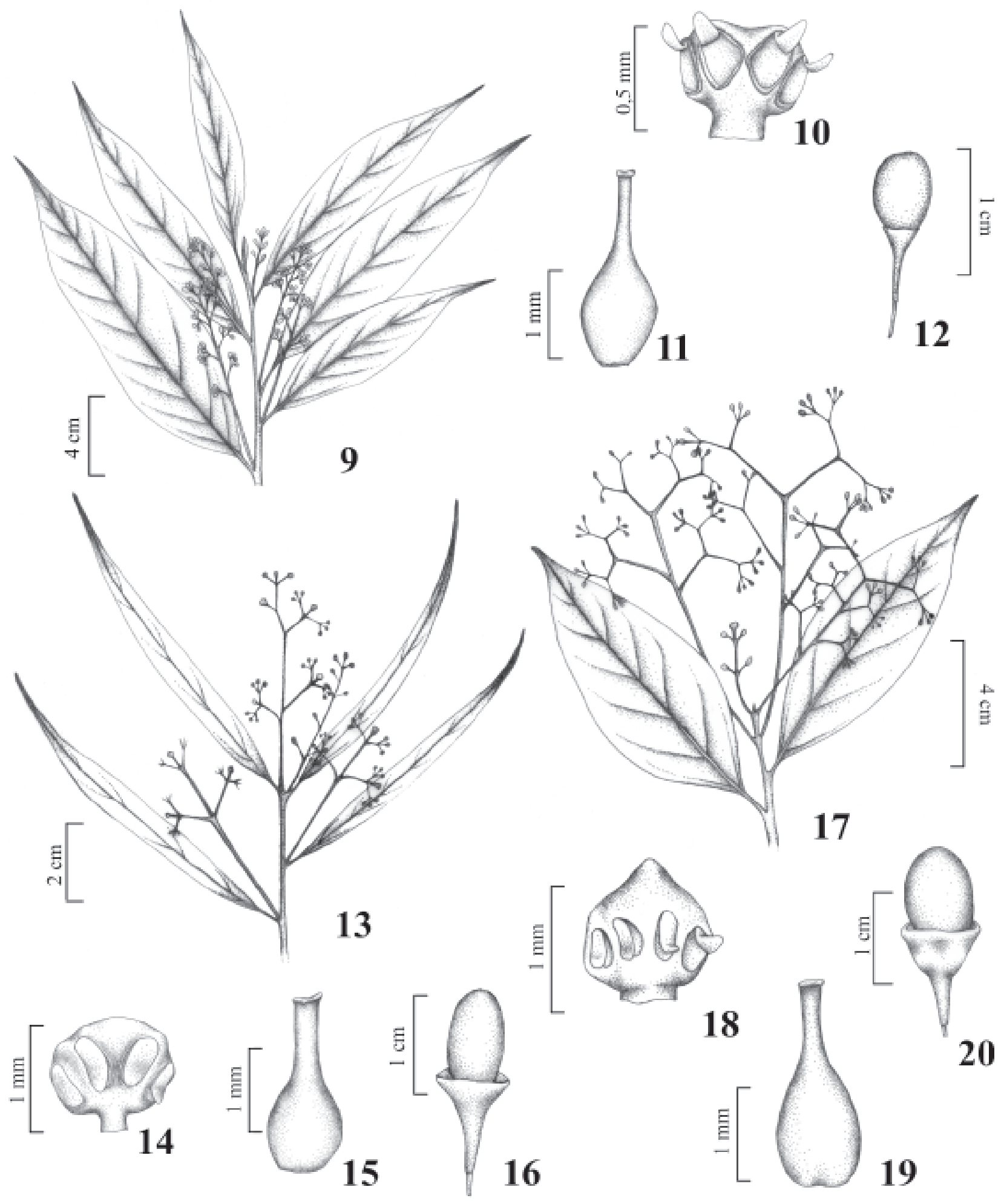

Figuras 9-20. 9-12. Nectandra cuspidata Nees. 9. Ramo com flores. 10. Estame da série I. 11. Pistilo. 12. Fruto (Conceição 2024). 13-16. Nectandra falcifolia (Nees) J.A. Castigl. ex Mart. Crov. \& Picc. 13. Ramo com flores. 14. Estame da série I. 15. Pistilo. 16. Fruto (Amaral 94). 17-20. Nectandra gardneri Meisn. 17. Ramo com flores. 18. Estame da série I. 19. Pistilo. 20. Fruto (Alves 29). 
da série II com conectivo contraído formando um acume e estilete muito curto, cerca de $15 \%$ do pistilo ou menor.

6. Nectandra hihua (Ruiz \& Pav.) Rohwer, Flor. Neotr. Monograph. 60: 196. 1993.

Fig. 21-25

Árvore, até $14 \mathrm{~m}$ alt. Folhas alternas, lâminas (5-)12-22(-26)×(2-)3,5-6(-9,5) cm, 2,5-4,2 vezes mais longas que largas, ovadas, ovado-elípticas, largo-elípticas a lanceoladas, ápice acuminado, base curtamente atenuada, geralmente revoluta, margem inteira, levemente ondulada, face adaxial glabrescente a glabra, face abaxial glabrescente, nervuras laterais 6-8 pares, nervação eucampdódroma, no ápice geralmente broquidódroma, domácias entre a nervura primária e a secundária, em forma de tufos de tricomas em algumas folhas; pecíolo 10-20×1,5-2,3 mm, glabrescente, levemente achatado. Inflorescência 5-15 cm compr., tirsóide-paniculada, axilar ou terminal, comprimento igual ou menor que as folhas, tricomas curtos, levemente crespos e densos a esparsamente distribuídos, aumentando a densidade à medida que se aproxima da flor, pedúnculo $2-9,5 \mathrm{~cm}$ compr. Flores 6-12 mm diâm., tricomas curtos, densos no receptáculo, glabrescente no ápice, hipanto internamente com tricomas; tépalas subiguais, tépalas externas ovadas, $3-5,8 \times 2-4,5 \mathrm{~mm}$, tépalas internas elípticas, raramente pentagonais, 3,2-5,8×2-4,5 mm, ápice obtuso, densamente papilosas na face interna e na extremidade, pedicelo 2,5-6 mm compr.; conectivo dos estames das séries I e II com prolongamento igual ou superior a $50 \%$ do comprimento da antera, anteras densamente papilosas, filetes dos estames das séries I e II 1/5 do comprimento da antera ou mais curtos, anteras pentagonais a oval-triangulares, ápice obtuso a levemente agudo, antera dos estames da série II com conectivo fortemente contraído acima dos locelos formando um acume, anteras dos estames da série III obtrapeziformes, ápice obtuso a truncado, estaminódios conspícuos, clavados; pistilo ca. 2,3 mm compr., ovário globoso, glabro, estilete muito curto, ca. $15 \%$ do pistilo. Fruto ca. $13 \times 8 \mathrm{~mm}$, globoso a elíptico, ca. $15 \%$ envolvido pela cúpula, cúpula ca. $2 \times 6 \mathrm{~mm}$, pateriforme, pedicelo ca. $11 \mathrm{~mm}$ compr., engrossado.

Material examinado: BRASIL. Mato Grosso do Sul: Bodoquena, 23/V/2002, fl., Aragaki \& Resende 983 (CGMS). Bonito, 3/IX/1998, fl., Damasceno-Júnior et al. 1605 (CGMS); 7/XI/2001, fl., fr., Constantino 146 (HRCB); 29/VIII/1986, fl., Jaramillo s.n. (ESA 3733); 12/IX/2001, fl., fr., Oda 11 (CGMS); 10/VIII/2001, fl., Constantino 138 (HRCB); 3/X/2000, fl., Constantino 80 (HRCB); 3/IX/1998, fl., Damasceno-Júnior et al. 1599 (CGMS, HUFU); 10/IX/2001, fl., Nunes 2 (CGMS); 5/VII/2005, fl., Alves 39 (CGMS); 5/VIII/2005, fl., Alves
\& Amano 21 (CGMS); 15/IX/2001, fl., Pott 4229 (HMS); 26/VIII/2002, fl., Pott et al. 3737 (HMS); 9/XI/2002, fr., Pott 10549 (HMS). Campo Grande, 11/VII/1993, fl., Resende et al. 5 (CGMS); 2/X/1997, fl. Resende \& Dias 1366 (CGMS); 14/VIII/1990, fl., Resende 129 (CGMS); 23/VI/2001, fl., Pott 9131 (HMS); 25/IV/2002, fl., Pott et al. 9789 (HMS). Corumbá, 9/IX/1984, fl., Conceição 1578 (CGMS, COR, UB); 16/VII/2001, fl., Damasceno-Júnior 2468 (SPF). Costa Rica, 30/VIII/1998, fl., Resende s.n. (CGMS 7814); 28/VI/2001, fl., Pott 9186 (CGMS, HMS). Dourados, 27/IX/2001, fr., Sciamarelli et al. 1049 (CGMS); 28/X/1999, fl., Sciamarelli \& Pereira 773 (DDMS); 24/VIII/1999, fl., Sciamarelli \& Pereira 756 (DDMS). Nioaque, 5/IX/2003, fl., fr., Pott et al. 11437 (CGMS, HMS). Porto Murtinho, 26/IX/1996, Ratter et al. s.n. (UB 7543). Rio Brilhante, 9/VII/2001, fl., Sciamarelli et al. 877(CGMS). Rio Negro, 30/VIII/1998, fl., Resende 1517 (HUFU). Três Lagoas, 13/VIII/1994, fl., Jacques 310 (CEUL).

Nectandra hihua possui a mais ampla distribuição geográfica do gênero, alcançando do oeste do México e Antilhas à região central do Brasil (Rohwer 1993b), sul do Mato Grosso do Sul e norte do Paraná. No Mato Grosso do Sul, a espécie é encontrada na floresta ombrófila densa aluvial e floresta estacional semidecidual nas regiões central, sudoeste, oeste, norte e leste. Coletada com flores de maio a outubro e com frutos de setembro a outubro.

Nectandra hihua carece de uma característica vegetativa peculiar para fins de identificação. A espécie pode ser reconhecida pela diferença morfológica entre os estames das séries I e II, onde as anteras dos estames da série I são maiores e possuem conectivo não contraído na extremidade (Fig. 23), enquanto as anteras dos estames da série II são menores e possuem conectivo contraído na extremidade (Fig. 24). Essas características podem ser extremamente úteis quando usadas em combinação com outras, como estilete muito curto, cerca de $15 \%$ do tamanho do pistilo, e domácias geralmente presentes nas folhas.

No Mato Grosso do Sul, a espécie pode ser confundida com $N$. gardneri, porém $N$. hihua, tem anteras dos estames da série II com conectivo contraído, formando um acume e estilete muito curto, cerca de $15 \%$ do pistilo ou menor. Em $N$. gardneri os estames da série II têm o conectivo não contraído e estilete levemente menor que o ovário, cerca de $45 \%$ do pistilo.

7. Nectandra megapotamica (Spreng.) Mez, Bull. Herb. Boissier, sér. 2, 2: 824. 1902.

Fig. 26-29

Árvore, até $10 \mathrm{~m}$ alt. Folhas alternas, lâminas (6,5-)8$14(-15) \times(1,5-) 2-3(-3,5) \mathrm{cm}, 4-6,5$ vezes mais longas que 
largas, estreito-elípticas, oblanceoladas a lanceoladas, ápice acuminado a caudado, base levemente atenuada a aguda, margem inteira, raramente revoluta, face adaxial glabrescente, face abaxial com tricomas, esparsos, curtos e adpressos, nervuras laterais 5-12 pares, nervação eucamptódroma, ápice geralmente broquidódroma, domácias entre a nervura primária e a secundária, em forma de tufos de tricomas em poucas folhas, pecíolo 4-12×0,6-1,5 mm, glabrescente, canaliculado. Inflorescência 4-9 cm compr., tirsóide-paniculada, axilar ou terminal, comprimento igual a menor que as folhas, tricomas curtos, adpressos a eretos e esparsos, mais denso no receptáculo, diminuindo em direção às tépalas, pedúnculo 1,6-4 cm compr. Flores 4-6 mm diâm., coberto por tricomas curtos, adpressos e densos no receptáculo, hipanto internamente glabro; tépalas iguais, 2,5-3×1,2-1,4 mm, elípticas, ápice agudo, esparsamente papilosas na face interna e na extremidade, pedicelo 2-5 mm compr.; conectivo dos estames das séries I e II com prolongamento inferior a $45 \%$ do comprimento da antera, anteras esparsamente papilosas, filete dos estames das séries I e II 1/3 ou 1/2 do comprimento da antera, anteras quadrangulares a retangulares, ápice obtuso, apiculado, antera dos estames da série II com conectivo não contraído acima dos locelos, anteras dos estames da série III retangulares, ápice truncado, estaminódios conspícuos, capitados; pistilo ca. 1,9 mm compr., ovário globoso a elíptico, glabro, estilete levemente menor ou do mesmo tamanho do ovário, ca. 45 a $50 \%$ do pistilo. Fruto ca. $15 \times 10 \mathrm{~mm}$, globoso a elíptico, ca. $15 \%$ envolvido pela cúpula, cúpula ca. $3,3 \times 6 \mathrm{~mm}$, pateriforme, pedicelo ca. $9 \mathrm{~mm}$ compr., pouco engrossado.

Material examinado: BRASIL. Mato Grosso do Sul: Bodoquena, s.d., fl., Damasceno-Júnior 3768 (CGMS). Bonito, 29/XI/1999, Damasceno-Júnior \& Garcia 1825 (CGMS); 6/IX/2005, fl., Pott \& Pott 13351 (HMS); 10/IV/2005, fr., Pott \& Pott 9970 (HMS). Caarapó, 3/VIII/2001, fl., Sciamarelli \& Silva 901 (CGMS). Campo Grande, 1/XII/2003, fr., Garcez 150 (CGMS); 16/IX/2000, fr., Resende et al. 1138 (CGMS); 16/VIII/2005, fl., Alves 23 (CGMS); 16/VIII/2005, fl., Alves 22 (CGMS); 28/VIII/2005, fl., Alves 40 (CGMS); Dourados, 27/IX/2001, fr., Sciamarelli et al. 1038 (CGMS); 6/VI/1996, Almeida \& Mattos s.n. (ESA 34485); 11/XI/1999, fr., Gomes et al. s.n. (CGMS 9740); 20/VII/1999, fl., Sciamarelli \& Pereira 745 (DDMS); 4/V/1996, veg. Almeida \& Mattos s.n. (DDMS). Maracajú, 29/XII/1973, fr., Sucre 10483 (CGMS). Ponta Porã, 10/VIII/2001, fl., Souza et al. 26778 (ESA).

Nectandra megapotamica ocorre do sul de Minas Gerais e região central do Mato Grosso do Sul até o Uruguai e Argentina (Rohwer 1993b). No Mato Grosso do Sul, a espécie ocorre nas regiões central e sul do estado, na floresta ombrófila densa aluvial e na floresta estacional semidecidual. Coletado com flores de maio a agosto e com frutos de julho a dezembro.

Nectandra megapotamica caracteriza-se pelas folhas estreito elípticas, oblanceoladas a lanceoladas, até 6,5 vezes mais longas que largas e anteras quadrangulares a retangulares, esparsamente papilosas e ápice apiculado. A espécie é próxima de $N$. falcifolia (Rohwer 1993b), porém $N$. megapotamica possui folhas 4-6,5 vezes mais longas que largas e filete dos estames das séries I e II com $1 / 3$ ou $1 / 2$ do comprimento da antera, cujo ápice é apiculado, enquanto $N$. falcifolia tem folhas 7-12 vezes mais longas que largas e o filete das anteras das séries I e II são 1/5 de seu comprimento ou menor, e ápice não apiculado.

8. Nectandra psammophila Nees, Syst. Laur. 303. 1836.

Fig. 30-33

Árvore, até $12 \mathrm{~m}$ alt. Folhas alternas, lâminas $(7,3-) 10-14(-16) \times(3-) 3,5-4(-5,2) \mathrm{cm}, 2,5-4$ vezes mais longo que largos, elípticas, estreito-elípticas a lanceoladas, ápice acuminado, base aguda, margem inteira, face adaxial glabra, face abaxial glabrescente, nervuras laterais 7-11 pares, nervação eucamptódroma, no ápice geralmente broquidódroma, domácias ausentes; pecíolo 4-11×0,8-2,4 mm, glabrescente, canaliculado. Inflorescência 4-8 cm compr., racemiforme, axilar, comprimento menor que as folhas, esparso-serícea, pedúnculo 1,8-2,5 cm compr. Flores 6-7 mm diâm., esparso-serícea, hipanto internamente glabro; tépalas iguais, $2,8 \times 2 \mathrm{~mm}$, oblongas, ápice agudo a arrendondado, densamente papilosas na face interna, pedicelo 1,7-3 mm compr.; conectivo dos estames das séries I e II com prolongamento inferior a $45 \%$ do comprimento da antera, anteras densamente papilosas, filete dos estames das séries I e II 1/5 do comprimento da antera ou mais curtos, anteras transverso-elípticas a suborbiculares, ápice arredondado, emarginado a truncado, antera dos estames da série II com conectivo não contraído acima dos locelos, anteras dos estames da série III obtrapeziformes, ápice truncado, estaminódios conspícuos, clavados; pistilo ca. 1,8 mm compr., ovário globoso, glabro, estilete menor que o ovário, ca. $20 \%$ do pistilo. Fruto ca. $13 \times 8,5 \mathrm{~mm}$, elíptico, ca. $25 \%$ envolvido pela cúpula trompetiforme, ca. $3,2 \times 8,5 \mathrm{~mm}$, pedicelo ca. $7 \mathrm{~mm}$ compr., engrossado.

Material examinado: BRASIL. Mato Grosso do Sul: Corumbá, 29/VI/1997, fl., fr., Pereira 2 (COR); Corumbá, 2/XII/2006, fl., Alves et al. 50 (CGMS); Corumbá, 2/XII/2006, fl., Alves et al. 51 (CGMS).

Nectandra psammophila é encontrada no Brasil, Bolívia e Colômbia. No Mato Grosso do Sul, a espécie 
possui registros de coletas apenas na floresta ombrófila densa aluvial na região oeste, no município de Corumbá. Segundo Killen (1993), a espécie na Bolívia também ocorre nesta formação. Coletada com flores e frutos em junho.
Nectandra psammophila apresenta poucas características diagnósticas, sendo geralmente confundida $\operatorname{com} N$. megapotamica. Em N. psammophila os filetes dos estames das séries I e II têm 1/5 do comprimento das anteras ou menor e estilete cerca de
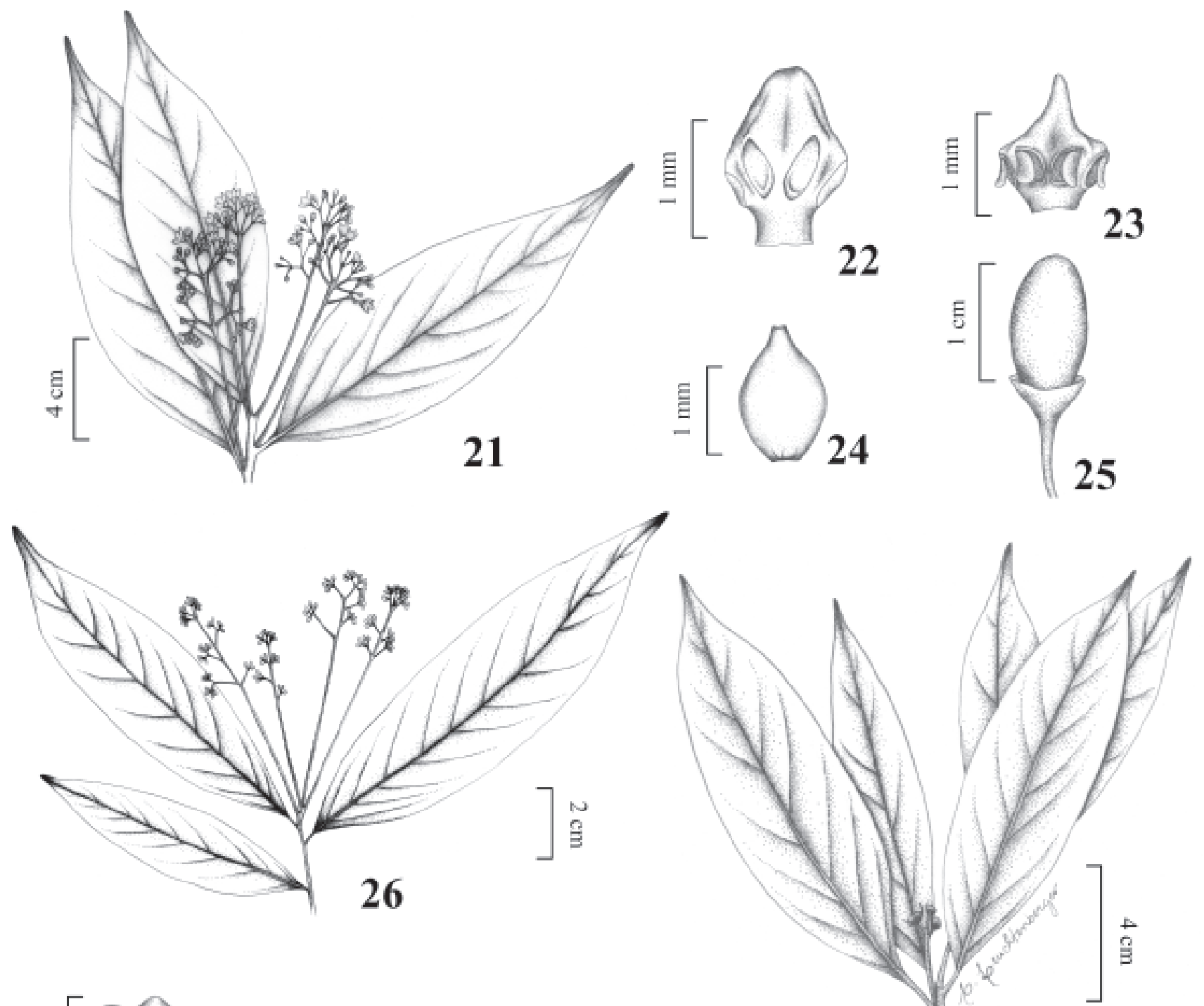

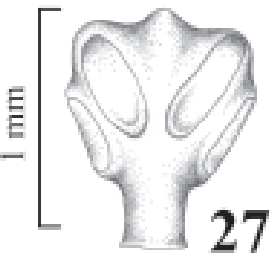

27
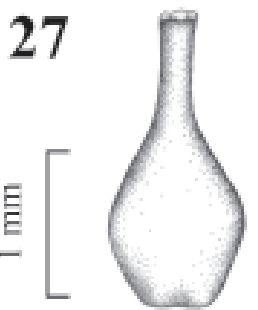

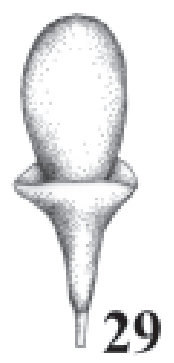

28
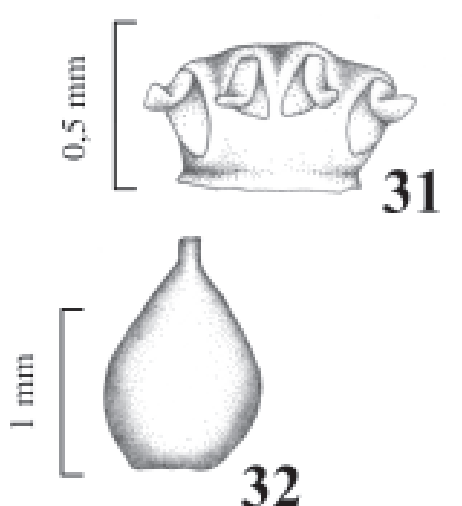

23

30

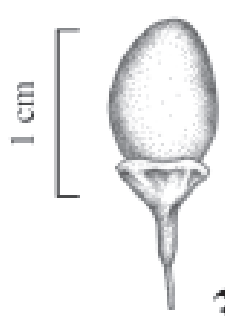

Figuras 21-33. 21-25. Nectandra hihua (Ruiz \& Pav.) Rohwer. 21. Ramo com flores. 22. Estame da série I. 23. Estame da série II. 24. Pistilo. 25. Fruto (Conceição 1578). 26-29. Nectandra megapotamica (Sprengel) Mez. 26. Ramo com flores. 27. Estame da série I. 28. Pistilo. 29. Fruto (Alves 23). 30-33. Nectandra psammophila Nees. 30. Ramo com frutos. 31. Estame da série I. 32. Pistilo. 33. Fruto (Alves 50). 
$20 \%$ do tamanho do pistilo, enquanto em $N$. megapotamica os filetes dos estames das séries I e II são $1 / 3$ ou $1 / 2$ do comprimento das anteras e estilete cerca de $50 \%$ do tamanho do pistilo.

Segundo Baitello et al. (2003) e Assis et al. (2005) uma característica peculiar da espécie no estado de São Paulo e Minas Gerais, respectivamente, é a presença de domácias axilares, porém essa característica não foi encontrada nos espécimes coletadas no Mato Grosso do Sul.

\section{Agradecimentos}

Os autores agradecem aos curadores dos herbários, pelo apoio e empréstimo do material para o estudo; à bolsa do primeiro autor concedida pela Conservation International (CI-Brasil); à Caroline Leuchtenberger, pela confecção das ilustrações; à coordenação do Mestrado em Biologia Vegetal da UFMS e à Pró-Reitoria de Pesquisa e Pós-Graduação, pelo auxílio às excursões de campo.

\section{Referências bibliográficas}

Allen, C.K. 1966. Notes on Lauraceae of tropical America I. The generic status of Nectandra, Ocotea and Pleurothyrium. Phytologia 13: 221-231.

Alves, F.M. \& Ishii, I.H. 2007. Lauraceae no município de Corumbá, Mato Grosso do Sul, Brasil. Rodrigésia 58: 179-192.

Assis, L.C.S.; Forzza, R.C. \& van der Werff, H. 2005. A família Lauraceae na reserva biológica da Represa do Grama, Descoberto. Brasil. Boletim de Botânica 23: 113-139.

Baitello, J.B. 2001. Novas espécies de Lauraceae para a flora brasileira. Acta Botanica Brasilica 14: 445-450.

Baitello, J.B. \& Coe-Teixeira, B. 1987. Flora fanerogâmica da reserva do parque estadual das Fontes do Ipiranga (São Paulo, Brasil). Hoehnea 14: 63-74.

Baitello, J.B.; Lorea-Hernández, F.G.L.; Moraes, P.L.R.; Esteves, R. \& Marcovino, J.R. 2003. Lauraceae. Pp. 149-223. In: M.G.L. Wanderley; G.J. Shepherd; A.M. Giulietti \& T.S. Melhem (eds.). Flora Fanerogâmica do Estado de São Paulo. v.3. São Paulo, FAPESP-Rima.

Barroso, G.M.; Guimarães, E.F.; Ichaso, C.L.F.; Costa, C.G. \& Peixoto, A.L. 2002. Sistemática de angiospermas do Brasil. v.1. 2 ${ }^{\mathrm{a}}$ ed. Viçosa, Universidade Federal de Viçosa.

Barroso, L.J. 1949. Chave para determinação de gêneros indígenas e exóticos da família Lauraceae no Brasil. Rodriguésia 12: 137-146.

Battilani, J.L.; Scremim-Dias, E. \& Souza, A.L.T. 2005. Fitossociologia de um trecho de mata ciliar do rio da Prata, Jardim, MS, Brasil. Acta Botanica Brasilica 19: 597-608.

Bernardi, L. 1962. Lauráceas. Talleres Graficos Universitarios. Mérida.

Chanderbali, A.S.; van der Werff, H. \& Renner, S.S. 2001. The relationships and historical biogeography of Lauraceae: evidence from the chloroplast and nuclear genomes. Annals of the Missouri Botanical Garden 88: 104-134.

Coe-Teixeira, B. 1975. Espécies novas de Nectandra (Lauraceae) da flora do Brasil. Acta Amazonica 5: 157-171.

Damasceno Júnior, G.A.; Nakajima, J.N.; Rezende, U.M. 2000. Levantamento florístico das cabeceiras dos rios Negro, Aquidauana, Taquari e Miranda no Pantanal, Mato Grosso do Sul, Brasil. Pp. 152-162. In: P.W. Willink; B. Chernoff; L.E. Alonso; J.R. Montambault \& R. Lourival. Uma avaliação biológica dos ecossistemas aquáticos do Pantanal, Mato Grosso do Sul, Brasil. Washington, DC., Conservation International.

Dubs, B. 1998. The botany of Mato Grosso: checklist of Angiosperms. séries B, n.3. Switzerland, Betrona-Verlag.

Font-Quer, P. 1953. Diccionario de botánica. Barcelona, Labor.
Harris, J.G. \& Harris, M.W. 1994. Plant identification terminology: an illustrated glossary. Utah, Spring Lake.

Hickey, L.J. 1973. Classification of the architecture of dicotyledonous leaves. American Journal of Botany 60: 17-33.

Holmgren, P.K.; Holmgren, N.H. \& Barnett, L.C. 1990. Index herbariorum: the herbaria of the world. $8^{\text {th }}$ ed. New York, New York Botanical Garden.

Killeen, T.J. 1993. Lauraceae. Pp. 368-387. In: T.J. Killeen; E.E. Garcia \& S.G. Beck (eds.). Guia de Arboles de Bolivia. La Paz, MBG.

Kostermans, A.J.G.H. 1957. Lauraceae. Reinwardtia 4: 193-256.

Kropf, M.S.; Quinet, A. \& Andreata, R.H.P. 2006. Lista anotada, distribuição e conservação das espécies de Lauraceae das restingas fluminenses, Brasil. Pesquisas: Botânica 57: 161-180.

Mez, C. 1889. Lauraceae Americanae. Jahrbuch Königlchen Botanischen Gartens 5: 1-556.

Madriñán, S. 2004. Lauraceae. Pp. 204-206. In: N. Smith; S.A. Mori; A. Henderson; D.W. Stevenson \& S.V. Heald (eds.). Flowering plants of the neotropics. Princeton, Princeton University Press.

Moraes, P.L.R. 2005. Sinopse das Lauráceas nos estados de Goiás e Tocantins, Brasil. Biota Neotrópica 5: 1-18.

Nees von Esenbeck, C.G.D. 1836. Systema laurinarum. Berlin, Veitii et Sociorum.

Pedralli, G.A. 1986. A família Lauraceae Lindley no Rio Grande do Sul, Brasil: Nectandra. Iheringia: Série Botânica 35: 133-149.

Pedralli, G.A. 1987. Lauráceas: Nectandra. Flora Ilustrada Catarinense. Itajaí, CETEM.

Pott, A.; Pott, V.J.; Sciamarelli, A.; Sartori, A.L.B.; Rezende, U.M.; ScremimDias, E.; Jacques, E.L.; Aragaki, S.; Nakajima, J.N.; Romero, R.; Cristaldo, A.C.M. \& Damasceno Júnior, G.A. 2006. Inventário de Angiospermas do complexo Aporé-Sucuriú. Pp. 45-66. In: T.C.S. Pogotto \& P.R. Souza. Biodiversidade do complexo Aporé-Sucuriú: subsídios à conservação e manejo do bioma Cerrado. Campo Grande, Editora-UFMS.

Quinet, A. 2005. Sinopse taxonômica da família Lauraceae no estado do Rio de Janeiro, Brasil. Acta Botanica Brasilica 19: 563-572.

Quinet, A. \& Andreata, R.H.P. 2002. Lauraceae Jussieu na reserva ecológica de Macaé de Cima, município de Nova Friburgo, RJ, Brasil. Rodriguésia 53: $59-121$.

Radford, A.E.; Dickison, W.C.; Massey, J.R. \& Bell, C.R. 1974. Vascular plant systematics. New York, Harper \& Row.

Rohwer, J.G. 1991. Borderline cases between Ocotea, Nectandra and Phoebe (Lauraceae): The "marginal" species of the Ocotea helicterifolia group, including the $O$. heydeana group. Botanische Jahrbücher Systematic 112: $365-397$.

Rohwer, J.G. 1993a. Lauraceae. Pp. 336-391. In: K. Kubitzki; J.G. Rohwer \& V. Bittrich (eds.). The families and genera of vascular plants. v. 2 . Magnoliid, Hamameliid and Caryophyliid families. Berlin, Springer-Verlag.

Rohwer, J.G. 1993b. Lauraceae: Nectandra. Flora Neotropica 60: 1-332.

Rohwer, J.G. 2000. Toward a phylogenetic classification of the Lauraceae: evidence from $m a t K$ sequences. Systematic Botany 25: 60-71.

Rohwer, J.G. \& Kubitzki, K. 1985. Entwicklungslinien im Ocotea-Komplex (Lauraceae). Botanische Jahrbücher Systematic 107: 129-135.

Rohwer, J.G. \& Kubitzki, K. 1993. Ecogeographical differentiation in Nectandra (Lauraceae), and its historical implications. Botanica Acta 106: 88-99.

Rohwer, J.G.; Richter, H.G. \& van der Werff, H. 1991. Two new genera of Neotropical Lauraceae and critical remarks on the generic delimitation. Annals of the Missouri Botanical Garden 78: 388-400.

Vattimo-Gil, I. 1956.Lauraceae do Itatiaia. Rodriguésia 18-19: 39-86.

Vattimo-Gil, I. 1966. Lauraceae do estado da Guanabara. Rodriguésia 25: 75-122.

Veloso, H.P. 1992. Manual técnico da vegetação brasileira. Rio de Janeiro, IBGE.

Vicentini, A.; van der Werff, H. \& Nicolau, S. 1999. Lauraceae. Pp. 150-179. In: J.E.L.S. Ribeiro; M.J.G. Hopkins; A. Vicentini; C.A. Sothers; M.A.S. Costa; J.M. Brito; M.A. Solza; L.H. Martins; L.G. Lohmann; P.A.C.L. Assunção; E.C. Pereira; C.F. Silva; M.R. Mesquita \& L.C. Procópio. Flora da reserva Ducke: guia de identificação das plantas vasculares de uma floresta de terra-firme na Amazônia central. Manaus, INPA.

van der Werff, H. 1984. Notes on neotropical Lauraceae. Annals of the Missouri Botanical Garden 71: 1180-1183.

van der Werff, H. 1991. A key to the genera of Lauraceae in the new world. Annals of the Missouri Botanical Garden 78: 377-387.

van der Werff, H. \& Richter, H.G. 1996. Toward an improved classification of Lauraceae. Annals of the Missouri Botanical Garden 83: 409-418.

Versão eletrônica do artigo em www.scielo.br/abb e http://www.botanica.org.br/acta/ojs 